\title{
Mitochondrial lineage MI traces an early human backflow to Africa
} Ana M González*†1, José M Larruga ${ }^{\dagger 1}$, Khaled K Abu-Amero², Yufei Shi², José Pestano ${ }^{3}$ and Vicente $M$ Cabrera ${ }^{1}$

Address: ${ }^{1}$ Department of Genetics, Faculty of Biology, University of La Laguna, Tenerife 38271, Spain, ${ }^{2}$ Department of Genetics, King Faisal Specialist Hospital \& Research Center, Riyadh 11211, Saudi Arabia and ${ }^{3}$ Department of Genetics, Faculty of Medicine, University of Las Palmas de Gran Canaria, Las Palmas 35080, Spain

Email: Ana M González* - amglez@ull.es; José M Larruga - jlarruga@ull.es; Khaled K Abu-Amero - kamero@kfshrc.edu.sa; Yufei Shi - yufei@kfshrc.edu.sa; José Pestano - jpestano@dbbf.ulpgc.es; Vicente M Cabrera - vcabrera@ull.es

* Corresponding author †Equal contributors

Published: 9 July 2007

BMC Genomics 2007, 8:223 doi:10.1/86/147|-2164-8-223
Received: 4 September 2006

Accepted: 9 July 2007

This article is available from: http://www.biomedcentral.com/I47I-2/64/8/223

(C) 2007 González et al; licensee BioMed Central Ltd.

This is an Open Access article distributed under the terms of the Creative Commons Attribution License (http://creativecommons.org/licenses/by/2.0), which permits unrestricted use, distribution, and reproduction in any medium, provided the original work is properly cited.

\begin{abstract}
Background: The out of Africa hypothesis has gained generalized consensus. However, many specific questions remain unsettled. To know whether the two $M$ and $N$ macrohaplogroups that colonized Eurasia were already present in Africa before the exit is puzzling. It has been proposed that the east African clade MI supports a single origin of haplogroup M in Africa. To test the validity of that hypothesis, the phylogeographic analysis of 13 complete mitochondrial DNA (mtDNA) sequences and $26 \mathrm{I}$ partial sequences belonging to haplogroup $\mathrm{MI}$ was carried out.
\end{abstract}

Results: The coalescence age of the African haplogroup $M I$ is younger than those for other $M$ Asiatic clades. In contradiction to the hypothesis of an eastern Africa origin for modern human expansions out of Africa, the most ancestral MI lineages have been found in Northwest Africa and in the Near East, instead of in East Africa. The MI geographic distribution and the relative ages of its different subclades clearly correlate with those of haplogroup U6, for which an Eurasian ancestor has been demonstrated.

Conclusion: This study provides evidence that MI, or its ancestor, had an Asiatic origin. The earliest MI expansion into Africa occurred in northwestern instead of eastern areas; this early spread reached the lberian Peninsula even affecting the Basques. The majority of the Mla lineages found outside and inside Africa had a more recent eastern Africa origin. Both western and eastern MI lineages participated in the Neolithic colonization of the Sahara. The striking parallelism between subclade ages and geographic distribution of MI and its North African U6 counterpart strongly reinforces this scenario. Finally, a relevant fraction of $\mathrm{Mla}$ lineages present today in the European Continent and nearby islands possibly had a Jewish instead of the commonly proposed Arab/Berber maternal ascendance.

\section{Background}

The reconstruction of human history is a multidisciplinary objective. Alternative models proposed to explain the origin and dispersion of modern humans on the basis of paleoanthropological data [1] have received uneven support from other disciplines. From a genetic perspective, uniparental non-recombining markers have depicted the most complete and coherent picture of the origin of 
modern humans, clearly favoring the recent out-of-Africa hypothesis. The greatest diversity and the deepest phylogenetic branches for both Y-chromosome [2,3] and mtDNA $[4,5]$ have been found in Africa. These African lineages have coalescence ages [6-9] compatible with a recent African origin of modern humans as proposed by fossil $[10,11]$ and archaeological studies [12]. Furthermore, only more derived lineages have been found out of Africa supporting the hypothesis that, in their worldwide dispersion, modern humans replaced archaic humans inside and outside Africa. It seems that radiation in Africa of Ychromosome M168 derived lineages [13] and L3 mtDNA lineages [14] preceded the out-of-Africa expansion. Focusing on mtDNA, all non-African lineages belong to two founder clusters, named $\mathrm{M}$ and $\mathrm{N}$, which share a common root with their L3 African counterpart. Two possible outof-Africa routes have been proposed: A southern coastal route bordering the Read Sea and an Eurasian continental route through the Levant. Based on mitochondrial phylogeography it was proposed that $\mathrm{M}$ lineages expanded with the coastal route to southern Asia and Oceania and N lineages by the continental route to Eurasia [7]. However, the posterior detection of primitive $\mathrm{N}$ lineages in southern areas as India $[15,16]$ and Australia $[6,17]$ weakened that hypothesis [18]. As, in addition, the founder ages of $M$ and $\mathrm{N}$ are very similar, the alternative hypothesis, that $\mathrm{M}$ and $\mathrm{N}$ founders derived from a single African migration, was favored by several authors [16,19-21]. Another related disjunctive yet not settled is whether $\mathrm{M}$ and $\mathrm{N}$ (and its main branch R) arose inside or outside Africa [20]. The detection of a basal branch of haplogroup $M$ in Africa (M1) gave support to the idea that haplogroup M originated in eastern Africa and was carried towards Asia with the out-of-Africa expansion [22]. The alternative hypothesis, that haplogroup M1 could trace a posterior backflow to Africa from Asia, considered by several authors $[7,21,23,24]$ has not yet gained experimental support because, until now, no ancestral M1 lineages have been found outside Africa $[21,24,25]$.

To shed light on this haplogroup we have constructed a phylogeny of the M1 clade based on the analysis of 13 complete or nearly complete mitochondrial sequences representing the main branches of $\mathrm{M} 1$ and realized a phylogeographic study using 261 partial M1 sequences to determine the most probable age and origin of this clade and the temporal and spatial frame of its secondary expansions in Africa and Eurasia.

\section{Results}

Although we have only completely sequenced a limited number of M1 lineages, the combination of HVSI haplotypes and RFLP status carried out for the rest of our M1 samples allow us to be confident that we have not missed any new basic M1 lineage.
As an outgroup of the M1 genomic phylogenetic tree (Fig. 1) we used a published Indian M30 complete sequence [25]. When this M30 lineage is compared to the rare M sequence previously detected in two Palestinians [26], it is evident that it belongs to the Indian super-clade M4'30, as it shares the basal mutation 12007. More specifically it belongs to the M30 branch because it also has transition 15431. M30 has a broad geographic, ethnic and linguistic range in India. It has been detected in northern and southern India, in Australoid and Caucasoids, and in Dravid and Indo-European speakers $[24,25]$. So, instead of an autochthonous Near East M lineage, its presence in Palestine is probably due to a recent gene flow from India. After careful re-reading and partial re-sequencing of two previously published M1 sequences [7], we have detected in them the following errors: both have the $12950 \mathrm{C}$ transversion, and, in addition M1,1 has the 6671 transition and M1,2 the 13111 transition. Taking these modifications into account, from the $M$ basal type, haplogroup $M 1$ is characterized by one transversion (12950C) and four transitions $(6446,6680,12403$, and 14110) in the coding region and by a five transitions motif $(195,16129,16189$, 16249 , and 16311) in the non-coding region (Fig. 1). This haplogroup can be RFLP diagnosed by a MnlI site loss at position 12402. Two main branches, M1c and M1abde, respectively defined by transitions 13111 and 6671, sprout from the root. Based on partial sequences M1c was defined by transition 16185 [21]. However, not all M1c lineages present this mutation that, in addition, recurrently appears in a M1b1 lineage. It seems that for population studies M1c could be better diagnosed by a DdeI site loss using a modified reverse primer (Table 1). It is surprising that none of the three M1c complete sequences have an eastern Africa ancestry: one (Jor771) has a Levantine origin and the other two belong to West sub-Saharan Africa (SER558) and West Mediterranean (VAL1881) areas. The latter two sequences conform a new M1c1 subclade defined by transitions 10895 and 16399 that can be RFLP diagnosed at 10895 position (Table 1). In relation to the M1abde cluster, it is also surprising that one lineage that directly branched out from the root (BER957) has a northwestern, not eastern, Berber ancestry. All the rest of lineages shared the 813 transition forming the Mlabd cluster. Again, an isolate offshoot of Basque ancestry (BASV82) sprouts from its root. Subclade M1b was characterized by an RFLP site gain $(+15882 \mathrm{AvaII})$ and loss of -15883 HaeIII [22]. Later an M1b subclade defined by the non-coding motif 16260-16320 and restricted to East Africans was identified [21]. Consistently, none of our M1b sequences from western areas has that motif. The last cluster, M1a, was first distinguished by RFLP +12345 RsaI [22] and, after that, further characterized by transition 16359 [21]. In addition it also has transition 3705 at its root (Fig. 1). M1a is the most prominent clade in eastern Africa. However, its expansion occurred later than the 
other M1 branches (Fig. 1). An M1a subclade, M1a2, defined by transition 9053, that can be RFLP diagnosed (Table 1), testifies a posterior spread of M1a to western Asia.

\section{Geographic distribution of $\mathrm{MI}$}

Figure 2 shows the reduced median network obtained from the $261 \mathrm{M} 1$ haplotypes found in a global search comprising more than 38,713 HVSI sequences. In Africa, haplogroup M1 has supra-equatorial distribution (see additional files 1 and 2). As previously reported its highest frequencies and diversities (Table 2) are found in Ethiopia in particular and in East Africa in general. Two appreciable gradients exist. Frequencies significantly diminished from East to West and also going South to sub-Saharan areas. M1 is not uncommon in the Mediterranean basin showing a peak in the Iberian Peninsula. However, it is rare in
Table I: Diagnostic RFLPs for different MI clusters

\begin{tabular}{|c|c|}
\hline Cluster & Diagnostic RFLP \\
\hline MI & - I $2402 \mathrm{Mnl}$ I (I) + I2950 Aci I, + | 4 I I 0 Ear I \\
\hline Mla & + I 2345 Rsal (2) \\
\hline MIb & -I5883 HaellI/+| 5882 Ava II (2) \\
\hline Mlc & $-|3| 10$ Dde I (3) \\
\hline $\mathrm{Mla2}$ & -9052 Hae II/-9053 Hha I \\
\hline MIbl & $-|5| 72 \mathrm{Hae}$ III \\
\hline $\mathrm{Mlcl}$ & + I0893 Taq I \\
\hline
\end{tabular}

$\mathrm{I}=[18]$

$2=[21,22]$

$3=$ The primers used in the amplification were: $L 13069=5^{\prime}$ AggCCCCACCCCAgTCTCAg $3^{\prime}$ and the modify $\mathrm{HI} 3 \mathrm{I}$ I $2^{*}=5^{\prime}$ gCTAgggggTggAAgCggATgACTA 3'

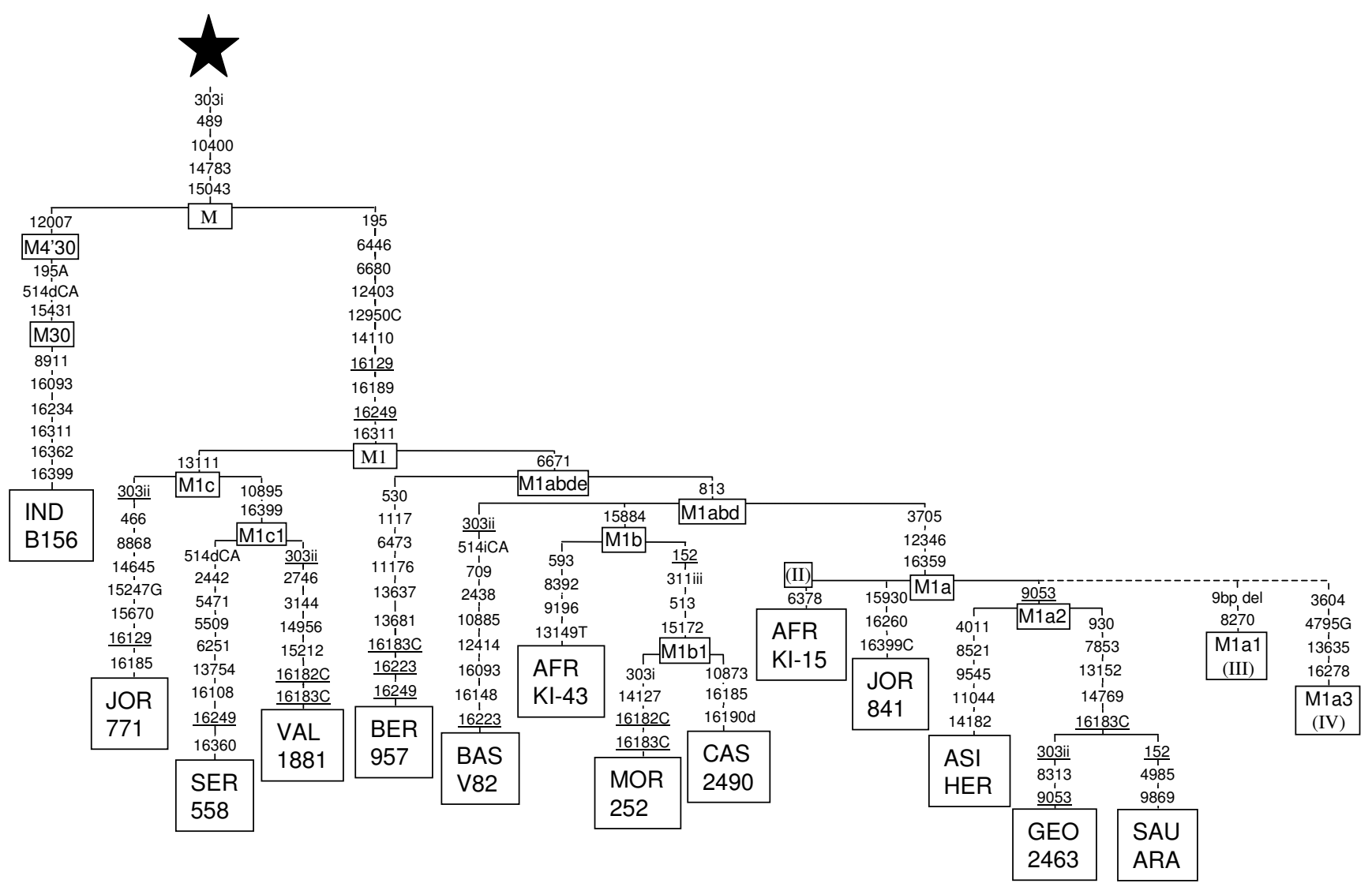

Figure I

Phylogenetic tree based on complete MI sequences. Numbers along links refer to nucleotide positions. C, G indicate transversions; "d" deletions and "i" insertions. Recurrent mutations are underlined. Star differs from rCRS [62, 63] at positions: 73, 263, 3 II I, 750, I438, 2706, 4769, 7028, 870I, 8860, 9540, I0398, I0873, II7I9, I2705, I4766, I530I, I5326, I6223 and 165I9. Subject origins are: Asian (ASI HER; [54]) and 2 Ethiopians (AFR-KI43 and AFR-KII5; [55]) only analyzed for coding region; Georgian (GEO 2463); Indian (IND-BI 56; [25]); 2 Jordanians (JOR 77I; [7] and JOR 84I); 2 Moroccans (MOR 252; [7] and BER 957 = Berber); Saudi Arab (SAU ARA); Serere from Senegal (SER 558); 3 Spanish (Basque = BAS V82, Castilian = CAS 2490, and Valencian = VAL I88I). Doted branches include subjects only analyzed for RFLP and HVI region [22]. Roman numbers refers to the Quintana-Murci et al. [22] nomenclature. 
continental Europe. Although in low frequencies, its presence in the Middle East has been well established from the South of the Arabian Peninsula to Anatolia and from the Levant to Iran. The central HVSI haplotype (1612916189-16223-16249-16311) has been found only once in northwestern India [27]. Another possible Indian M1 candidate is the derived sequence: 16086-16129-1622316249-16259-16311 [28]. However, in two recent studies in which 24 [24] and 56 [25] Indian M complete sequences were analyzed no ancestral M1 lineages have been found. M1 haplotypes have also been occasionally spotted in the Caucasus and the Trans Caucasus $[23,29]$ and in Central Asia [30]. It seems that, going east, M1 even reached the Tibet as the HVSI diagnostic motif was sampled there [31]. However, although haplotypes sharing four of the five HVSI transitions defining M1 (1612916223-16249-16278-16311-16362; 16129-1622316234-16249-16311-16362) have been sampled in Thailand and Han Chinese [32,33], complete sequencing have unequivocally allocated them in the $\mathrm{D} 4 \mathrm{a}$ branch of $D$, the most abundant haplogroup representing $M$ in East Asia. As commented previously, this is a clear example of the danger of establishing affinities between geographically distant areas only on the basis of HVSI homologies as, often, they are the product of geographic isolation and molecular convergence [18]. Within this sparse but geographically wide range of $\mathrm{M} 1$ distribution its three identified branches also had uneven radiations. Although M1a (HVSI identified by the 16359 transition) is present in all the $\mathrm{M} 1$ range, its greatest frequencies and diversities are found in Ethiopia and eastern Africa (Table 2), pointing to this area as the most probable origin of the M1a expansion in all directions, with particular incidence in western Asia and sub-Saharan Africa. Not all the M1b lineages can be HVSI identified; however, several specific subclades have different locations. Those characterized by transitions 16260-16320 [21], and by presence of 16182 transition and $16265 \mathrm{C}$ transversion [22] are restricted to Ethiopia with occasional spreads to eastern Africa. In addition, there is an M1b branch, identified by 16185 transition and 16190 deletion that has a northwestern distribution excepting a Jordan haplotype (Fig. 2). Despite that M1C cannot be unequivocally defined by transition 16185, it can be stated that M1c is an overwhelmingly Northwest African clade which spreads to the Mediterranean and West sub-Saharan Africa areas. Finally, other unclassified M1 branches have also different geographic ranges. Those identified by the presence of 16357 transition and by the reversion of the diagnostic position 16129 are of Ethiopian eastern Africa adscription, while clusters characterized by loss of the diagnostic position 16223 and by the 16399 transition have a northwestern distribution (Fig. 2). However, M1 assignation of haplotypes, which lack any of the basic positions, based only on HVSI information is risky when they share other diagnostic positions with different haplogroups. For instance, the Russian haplotype 16183C-16189-16249-16311, classified as M1 on the basis of its HVSI sequence [34] also matches with haplotypes assigned to the U1a clade [35].

The presence in the Mediterranean basin and in West subSaharan Africa of M1a and M1c lineages can be taken as proof that these areas received influences both from the West and East North African centers of M1 radiation. Quantitative confirmation of the above described patterns are provided by AMOVA and pairwise distances based on FST analyses using the groups and populations described in Material and Methods and taking into account haplotypic molecular differences. As usual the bulk of the variation, $90 \%$, is within populations, $6 \%$ is due to differences among groups and $4 \%$ to differences among populations within groups. Pairwise differences between populations (Table 3 ) offer a more detailed view. There is homogeneity between populations within eastern Africa, small differences $(p<0.05)$ within western Africa and strong heterogeneity between these main areas $(p<$ $0.001)$. On the contrary, Iberian Peninsula has significant differences with the rest of Europe. In turn, West Asia conforms an homogenous continuum with East Africa and Europe excepting Iberian Peninsula and the latter is not significantly different of western Africa. All these results can be explained as due to the differential radiation of M1a from East Africa and M1c from Northwest Africa, the Iberian Peninsula being mostly influenced by Northwest Africa and the rest of Europe and western Asia by East Africa.

\section{MI haplotypes in Jews}

Several M1 haplotypes have been detected in Jewish communities albeit in low frequencies [36,37]. However, when compared with non-Jew populations they show significantly higher frequencies for the whole M1 haplogroup $\left(\mathrm{p}=33.54^{* * *}\right)$ and for M1a in particular $(\mathrm{p}=$ $\left.24.90^{* * *}\right)$. The only striking exception is that of the Moroccan Jews for which no M1 lineages have been detected at all [36]. Interestingly, all M1 lineages found in Jews, except two, belong to the eastern clade M1a (Fig. 2). Therefore, as for the bulk of the M1 Near East haplotypes, the most probable origin of these Jewish M1 lineages is the result of an eastern African expansion around 5000 years ago. Another peculiarity of M1 in Jewish communities is its reduced haplotypic diversity (Table 2) which has been already detected for other mtDNA lineages $[36,38]$. In addition, there is a strong $\mathrm{M} 1$ geographic differentiation among Jewish communities. For example, all European Ashkenazi Jews have only one M1a lineage characterized by a transition in the 16289 position that has not been detected in other Jew or non-Jew populations. Similarly, all West Asian Jews shared an identical M1a motif characterized by a transition in the 16209 posi- 
Table 2: Total of individuals sampled and frequencies, nucleotide diversity and gene diversity for MI and Mla clusters. a) local, b)Jew and c) total individuals.

\begin{tabular}{|c|c|c|c|c|c|c|c|c|c|}
\hline $\begin{array}{l}\text { a) } \\
\text { namea }\end{array}$ & $\begin{array}{l}\text { Locals } \\
\text { sample }\end{array}$ & $\mathrm{nM} \mathrm{I}^{\mathrm{b}}$ & $\% M I$ & $\mathrm{pi}^{*} 1000$ & $h(\%)$ & nMla & $\% \mathrm{Mla}$ & $p^{i * 1000}$ & $h(\%)$ \\
\hline \multicolumn{10}{|l|}{ Europe } \\
\hline IPE & 5007 & 34 & 0.7 & $5.6 \pm 3.8$ & $84 \pm 3$ & 10 & 29 & $1.4 \pm 1.7$ & $38 \pm 18$ \\
\hline MEU & 3278 & 15 & 0.5 & $5.5 \pm 3.9$ & $76 \pm 10$ & 9 & 60 & $3.0 \pm 2.7$ & $42 \pm 19$ \\
\hline REU & 10735 & 1 & 0.0 & - & - & I & 100 & - & - \\
\hline TEU & 19020 & 50 & 0.3 & $5.8 \pm 3.9$ & $84 \pm 3$ & 20 & 40 & $2.5 \pm 2.2$ & $45 \pm 14$ \\
\hline \multicolumn{10}{|l|}{ Africa } \\
\hline NWA & 1175 & 38 & 3.2 & $3.9 \pm 2.9$ & $70 \pm 7$ & 2 & 5 & $0.0 \pm 0.0$ & $0 \pm 0$ \\
\hline CWA & 2351 & 7 & 0.3 & $7.2 \pm 5.3$ & $86 \pm 14$ & 1 & 14 & - & - \\
\hline NEA & 288 & 23 & 8.0 & $5.7 \pm 3.9$ & $85 \pm 5$ & 13 & 57 & $4.9 \pm 3.7$ & $78 \pm 10$ \\
\hline ETH & 344 & $53(78)$ & 15.4 & $9.4 \pm 5.6$ & $92 \pm 2$ & 45 & 58 & $5.5 \pm 3.7$ & $82 \pm 5$ \\
\hline CEA & 533 & $61(86)$ & 11.4 & $9.1 \pm 5.5$ & $92 \pm 2$ & 48 & 56 & $5.4 \pm 3.7$ & $81 \pm 5$ \\
\hline WA & 3526 & 45 & 1.3 & $4.5 \pm 3.2$ & $75 \pm 6$ & 3 & 7 & $0.0 \pm 0.0$ & $0 \pm 0$ \\
\hline EA & 821 & $84(109)$ & 10.2 & $8.5 \pm 5.2$ & $92 \pm 2$ & 61 & 56 & $5.5 \pm 3.7$ & $81 \pm 5$ \\
\hline SEA & 4347 & $129(154)$ & 3.0 & $7.9 \pm 4.9$ & $91 \pm 1$ & 64 & 42 & $5.2 \pm 3.6$ & $79 \pm 5$ \\
\hline \multicolumn{10}{|l|}{ Asia } \\
\hline WAS & 7589 & $36(28)$ & 0.5 & $5.5 \pm 3.8$ & $78 \pm 8$ & 18 & 64 & $2.8 \pm 2.4$ & $49 \pm 14$ \\
\hline \multicolumn{10}{|l|}{ Total } \\
\hline TOT & 30956 & $215(232)$ & 0.7 & $7.2 \pm 4.5$ & $89 \pm 1$ & 102 & 44 & $4.4 \pm 3.1$ & $69 \pm 5$ \\
\hline EAs & 5912 & 0 & 0.0 & - & - & - & - & - & - \\
\hline SAf & 596 & 0 & 0.0 & - & - & - & - & - & - \\
\hline b) & Jews & & & & & & & & \\
\hline name $e^{a}$ & sample & $\mathrm{nM} / \mathrm{b}$ & $\% M I$ & $p^{i * 1000}$ & $h(\%)$ & $\mathrm{nMla}$ & $\% \mathrm{Mla}$ & $\mathrm{pi}^{\mathrm{*}} 1000$ & $h(\%)$ \\
\hline \multicolumn{10}{|l|}{ Europe } \\
\hline JIP & 48 & 2 & 4.2 & $3.6 \pm 5.1$ & $100 \pm 50$ & 2 & 100 & $3.6 \pm 5.1$ & $100 \pm 50$ \\
\hline JRE & 663 & 6 & 0.9 & $0.0 \pm 0.0$ & $0 \pm 0$ & 6 & 100 & $0.0 \pm 0.0$ & $0 \pm 0$ \\
\hline JTE & 711 & 8 & 1.1 & $2.5 \pm 2.4$ & $46 \pm 20$ & 8 & 100 & $2.5 \pm 2.4$ & $46 \pm 20$ \\
\hline \multicolumn{10}{|l|}{ Africa } \\
\hline JNWA & 135 & 0 & 0.0 & - & - & - & - & - & - \\
\hline JNEA & 20 & 0 & 0.0 & - & - & - & - & - & - \\
\hline JET & 69 & 14 & 20.3 & $5.7 \pm 4.0$ & $81 \pm 7$ & 12 & 86 & $3.8 \pm 3.1$ & $76 \pm 8$ \\
\hline JCEA & 69 & 14 & 20.3 & & & 12 & 86 & & \\
\hline JEA & 89 & 14 & 15.7 & & & 12 & 86 & & \\
\hline JSEA & 224 & 14 & 6.3 & & & 12 & 86 & & \\
\hline \multicolumn{10}{|l|}{ Asia } \\
\hline JAS & 473 & 7 & 1.5 & $0.0 \pm 0.0$ & $0 \pm 0$ & 7 & 100 & $0.0 \pm 0.0$ & $0 \pm 0$ \\
\hline \multicolumn{10}{|l|}{ Total } \\
\hline JEW & 1408 & 29 & 2.1 & $6.3 \pm 4.2$ & $86 \pm 3$ & 27 & 93 & $5.6 \pm 3.8$ & $84 \pm 3$ \\
\hline c) & Totals & & & & & & & & \\
\hline name $e^{a}$ & sample & $\mathrm{nM} / \mathrm{b}$ & $\% M I$ & $p^{i * 1000}$ & $h(\%)$ & $\mathrm{nMla}$ & $\% \mathrm{Mla}$ & $p^{i * 1000}$ & $h(\%)$ \\
\hline \multicolumn{10}{|l|}{ Europe } \\
\hline $\mathrm{IPEj}$ & 5055 & 36 & 0.7 & $5.7 \pm 3.8$ & $84 \pm 3$ & 12 & 33 & $1.7 \pm 1.8$ & $44 \pm 16$ \\
\hline REUj & 11398 & 7 & 0.1 & $2.1 \pm 2.2$ & $29 \pm 20$ & 7 & 100 & $2.1 \pm 2.2$ & $29 \pm 20$ \\
\hline TEUj & $1973 \mid$ & 58 & 0.3 & $6.2 \pm 4.1$ & $86 \pm 3$ & 28 & 48 & $3.3 \pm 2.6$ & $64 \pm 9$ \\
\hline \multicolumn{10}{|l|}{ Africa } \\
\hline NWA & 1310 & 38 & 2.9 & & & 2 & 5 & & \\
\hline NEA & 308 & 23 & 7.5 & & & 13 & 57 & & \\
\hline ETHj & 413 & $67(92)$ & 16.2 & $9.1 \pm 5.5$ & $92 \pm 2$ & 57 & 62 & $5.4 \pm 3.6$ & $82 \pm 4$ \\
\hline CEAj & 602 & $75(100)$ & 12.5 & $8.9 \pm 5.4$ & $92 \pm 2$ & 60 & 60 & $5.3 \pm 3.6$ & $81 \pm 4$ \\
\hline$E A j$ & 910 & $98(123)$ & 10.8 & $8.4 \pm 5.1$ & $92 \pm 2$ & 73 & 59 & $5.4 \pm 3.7$ & $82 \pm 4$ \\
\hline SEAj & 4571 & $143(168)$ & 3.1 & $8.0 \pm 4.9$ & $92 \pm 1$ & 78 & 45 & $5.5 \pm 3.7$ & $81 \pm 4$ \\
\hline \multicolumn{10}{|l|}{ Asia } \\
\hline WASj & 8062 & $43(35)$ & 0.5 & $5.7 \pm 3.9$ & $82 \pm 5$ & 25 & 71 & $3.6 \pm 2.3$ & $67 \pm 9$ \\
\hline \multicolumn{10}{|l|}{ Total } \\
\hline ТОТј & 32364 & $244(261)$ & 0.8 & $7.4 \pm 4.6$ & $90 \pm 1$ & 129 & 49 & $4.8 \pm 3.3$ & $77 \pm 4$ \\
\hline
\end{tabular}

a Name for locals, Jews and total for different areas: Europe: Iberian Peninsula and related Islands (IPE, JIP, IPEj), Europe Mediterranean area (MEU), Rest of Europe (REU, JRE, REUj), and total Europe (TEU, JTE, TEUj); Africa: Northwest Africa (NWA, JNWA), Central West Africa (CWA), Northeast Africa (NEA, JNEA), Ethiopia (ETH, JET, ETHj), Central East Africa (CEA, JCEA, CEAj), East Africa (EA, JEA, EAj), West Africa (WA) and Supra-Equatorial Africa (SEA, JSEA, SEAj); Asia: West Asia (WAS, JAS, WASj); Total of these samples (without South Africa and East Asia) (TOT, JEW, TOTj); East Asia (EAs); South Africa (SAf).

b Number outside and inside the parenthesis were used to estimate the MI and Mla frequency, respectively. 


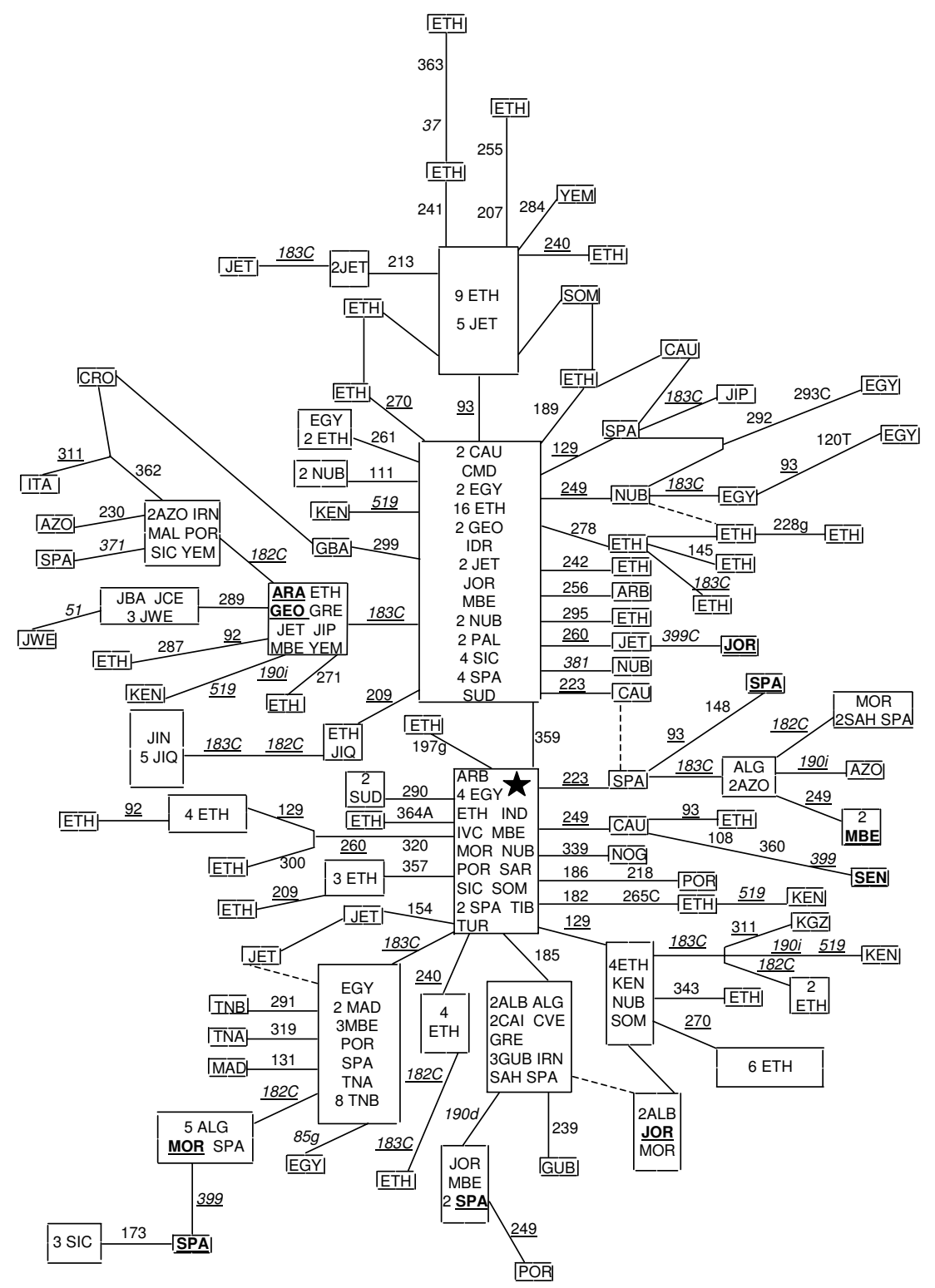

Figure 2

Reduced median network relating MI HVSI sequences. The central motif (star) differs from rCRS at positions: I6I29 I6I89 I6223 16249 163 I I for HVI control region. Numbers along links refer to nucleotide positions minus I6000: homoplasic mutations are underlined, and positions not used in diversity estimations are in italics. The broken lines are less probable links in accordance with completed sequences (Fig. I) and/or mutation recurrence. Size of boxes is proportional to the number of individuals included. Codes are: NWA = Northwest Africa (ALB = Algerian Berber; ALG = Algerian; MBE = Moroccan Berber; MOR = Moroccan; SAH = Saharan; TNA = Tunisia Arab; TNB = Tunisia Berber); CWA = Central West Africa (GUB = Guinea Bissau; IVC = Ivory Coast; $M A L=$ Mali; SEN = Senegalese); NEA = Northeast Africa (EGY = Egyptian; NUB = Nubian; SUD = Sudanese); $C E A=$ Central East Africa $(E T H=$ Ethiopian; $K E N=$ Kenyan; SOM = Somali); WAS = West Asia (ARA = Arab; $A R B$ = Arab Bedouin; CAU = Caucasian; GEO = Georgian; JOR = Jordanian; IDR = Israel Druze; IND = Indian; IRN = Iranian; KGZ = Kirghiz; NOG = Nogay; PAL = Palestinian; TIB = Tibetan; TUR = Turkish; YEM = Yemeni); IPE = Iberian Peninsula and islands (AZO = Azores; CAI = Canary Islander; CVE = Cape Verde; MAD = Madeira islander; POR = Portuguese; SPA = Spanish); MEU = Mediterranean Europe (CRO = Croatian; CMD = Central Mediterranean; GRE = Greek; ITA = Italian; SAR = Sardinian; $\mathrm{SIC}=$ Sicilian); REU = Rest of Europe (GBA = English); JEW = Jews (JBA = Baltic Jew; JCE = Central Europe Jew; JET = Ethiopian Jew; JIQ = Iraqi Jew; JIN = Iranian Jew; JIP = Spanish Jew; JWE = Western Europe Jew). In boldface and underlined individual complete sequenced. 
Table 3: Population pairwise $\mathbf{F}_{\mathrm{ST}} \mathbf{s}$ based on $\mathrm{MI}$ haplotypes.

\begin{tabular}{|c|c|c|c|c|c|c|c|c|c|}
\hline Populations & MEU & IPE & NWA & CWA & NEA & CEA & WA & EA & WAS \\
\hline MEU & - & $0.09 *$ & 0.31 *** & $0.27^{* *}$ & 0.03 & $0.05^{*}$ & $0.28 * * *$ & $0.04^{*}$ & 0.01 \\
\hline IPE & & - & 0.02 & 0.08 & $0.09 * *$ & $0.09 * * *$ & 0.02 & $0.08 * * *$ & $0.08^{* *}$ \\
\hline NWA & & & - & $0.12^{*}$ & $0.26 * * *$ & $0.18^{* * * *}$ & 0.00 & $0.18 * * *$ & $0.27 * * *$ \\
\hline CWA & & & & - & $0.26 * *$ & $0.20 * *$ & 0.05 & $0.21 * * *$ & 0.26 ** \\
\hline NEA & & & & & - & 0.02 & $0.24 * * *$ & 0.01 & 0.00 \\
\hline CEA & & & & & & - & $0.19 * * *$ & 0.00 & 0.02 \\
\hline WA & & & & & & & - & $0.18 * * *$ & $0.25 * * *$ \\
\hline EA & & & & & & & & - & 0.01 \\
\hline WAS & & & & & & & & & - \\
\hline
\end{tabular}

$*=p<0.05 ; * *=p<0.01 ; * * *=p<0.001$

Abbreviated name populations as in table 2

tion that has been detected only once in Ethiopia. These results are congruent with the proposition that, in the majority of the cases, Jewish migrations implied strong maternal founder effects [36-38]. Nevertheless, as M1a Jewish lineages are unique and different in different groups, we think that its source Near East population should not suffer strong genetic bottlenecks. Finally, it is worth mentioning that $\mathrm{M} 1$ frequencies of Jewish groups and their host populations are significantly correlated $(\mathrm{r}=$ $0.942^{* *}$ ) which suggests that some genetic interchange must have happened between them as already proposed by others authors [36,37].

\section{Radiation ages and evolution of lineages}

Radiation ages for M1 and its subhaplogroups have been estimated on the basis of complete coding and HVSI sequences using different mutation rate estimations (Table 4). The ages obtained for M1 and M1a from HVSI data are more coherent with those calculated for the coding region using the Ingman et al. [6] mutation rate than that proposed by Mishmar et al. [8]. Our coalescence age estimations for the whole M1 clade $(20,000-30,000$ years) are younger than those previously published [22]; however, the approximate expansion ages for the eastern Africa M1a subclade $(10,000-20,000$ years) are in the same range. Although standard errors overlap, it seems that the northwestern Africa expansion represented by M1c subclade $(19,040 \pm 4916$ years $)$, preceded the M1a eastern Africa expansion $(16,756 \pm 5997) \mathrm{M} 1 \mathrm{~b}$ being the youngest branch $(10,155 \pm 3590)$. It must be stated that coalescence ages are only rough estimations biased by mutation rate estimations, small sample size, demographic history and, possibly, selection. There are recent examples of clock-like evolution violations in several mtDNA lineages that have been explained by selective or demographic effects [39-41]. Here, subclade M1a2 (Fig. 1) represents a new example of constant mutation rate violation. The mean number of substitutions accumulated in M1a2 lineages $(12.5 \pm 0.7)$ is significantly higher $(\mathrm{p}=$ $0.008)$ than that in the rest of M1 lineages $(8.4 \pm 1.3)$. This result is not compatible with a uniform rate of evolution. The small standard errors show that there is high lineage homogeneity within groups, which weakens the possibility that stochastic processes have played a main role. Different patterns of synonymous and nonsynonymous changes among different lineages have been taken as hints of a role for selection in other studies $[8,39]$. In our case differences between synonymous vs. nonsynonymous changes within groups does not reach statistical signification $(\mathrm{p}=0.75)$. However, the mean number of coding region substitutions accumulated in M1a2 lineages ( $11 \pm$ $0.0)$ is significantly higher $(\mathrm{p}<0.001)$ than in the rest of M1 (5.6 \pm 0.7$)$. Conversely, the mean number of regulatory region substitutions accumulated in M1a2 lineages $(1.5 \pm 0.7)$ is smaller than in the rest $(2.8 \pm 0.9)$ although not reaching statistical significance $(\mathrm{p}=0.175)$. If the mutation rate was constant along the whole mtDNA molecule, for each mutation in the regulatory region roughly fourteen mutations should accumulate in the coding region. However, selection pressure is higher in the coding than in the regulatory region so that the substitution rate is ten times faster in the latter. The mean coding/regulatory ratio is 8.3 for M1a2 lineages and only 2.4 for the rest of M1. We interpret these results as due to different ages of expansion between clades. M1a2 would be the youngest clade with a more recent expansion than the others so that purifying selection has not had enough time to eliminate mutations with small deleterious effects in the coding region. We think that differences in the rate of evolution among subgroups of the North African U6 haplogroup [40] could be better explained by the same pattern assuming that the U6a subclade, with the highest coding/regulatory ratio, had a more recent radiation than the U6b subclade. In spite of its anomalous behavior, M1a2 has only a minor effect on the estimation of the whole M1 coalescence age although its omission significantly diminishes that of the M1a subgroup (Table 4). 
Table 4: Estimated ages (years) for different subgroups of MI haplogroup, based on coding and HVSI regions.

\begin{tabular}{|c|c|c|c|c|c|c|c|}
\hline \multirow[b]{3}{*}{ Subgroup } & \multicolumn{5}{|c|}{ Complete sequences } & \multicolumn{2}{|c|}{ HVI sequences } \\
\hline & \multicolumn{3}{|c|}{ Coding region } & \multicolumn{2}{|r|}{ HVSI } & \multirow[b]{2}{*}{$N$} & \multirow[b]{2}{*}{ age } \\
\hline & $\mathrm{N}$ & age $^{a}$ & age $^{b}$ & $\mathrm{~N}$ & age & & \\
\hline MI & 13 & $26071 \pm 5297$ & $35175 \pm 7147$ & 10 & $30270 \pm 11767$ & 261 & $26365 \pm 13319$ \\
\hline MIwitout a2 & 10 & $21706 \pm 4457$ & $29286 \pm 6014$ & 8 & $32793 \pm 12358$ & & \\
\hline MIc & 3 & $19040 \pm 4916$ & $25689 \pm 6633$ & 3 & $33633 \pm|504|$ & & \\
\hline MIb & 3 & $10155 \pm 3590$ & $|370| \pm 4844$ & 2 & - & & \\
\hline Mla & 5 & $16756 \pm 5997$ & $22607 \pm 8091$ & 3 & $6727 \pm 6727$ & 129 & $14236 \pm 5124$ \\
\hline Mla without a2 & 2 & $3808 \pm 2693$ & $5138 \pm 3633$ & 1 & - & & \\
\hline
\end{tabular}

a.- mutation rate of Ingman et al. [6]

b.- mutation rate of Mishmar et al. [8]

\section{Discussion \\ Phylogeographic parallelism between MI and U6 haplogroups}

There are striking similarities between the geographical dispersals and radiation ages observed here for M1 lineages and those previously published for the North African U6 haplogroup [40]. It was proposed that U6a first spread was in Northwest Africa around 30,000 ya. Coalescence ages for $\mathrm{M} 1$ also fit into this period and the oldest clade M1c has an evident northwestern Africa distribution; however it had to have a wide geographic range as some M1c lineages are today still present in Jordanians (Figs. 1 and 2). It is curious that this prehistoric Near Eastern colonization was also pointed out by the uniqueness of the U6a haplotypes detected in that area. A posterior East to West African expansion around 17,000 ya was indicated by the U6a1 relative diversity and distribution. Again, age, relative East to West diversities and geographic range accurately correspond with the M1a1 expansion detected here. More recent local spread of lineages U6b and U6c also parallel the M1b and M1c1 distributions. Furthermore, these similarities also hold outside Africa. U6 lineages in the Iberian Peninsula have been considered traces of northward expansions from Africa. Based on the uneven distribution of U6a and U6b lineages in Iberia, with the former predominating in southern and the latter in northern areas, it was proposed that U6b in Iberia represents a signal of a prehistoric North African immigration whereas the presence of U6a could be better attributed to the long lasting historic Arab/Berber occupation [40]. Again, this pattern is accurately repeated by the M1C and M1a distribution in the Iberian Peninsula, the northwest African M1 being more abundant in northern areas (56\%) and the East African M1a in southern areas (85\%) although, due to the small sample size, difference does not reach a significant level $(\mathrm{p}=0.07)$. Additional support to the hypothesis of a prehistoric introduction are the recently detected presence of a Northwest African M1c lineage in a Basque cemetery dated to the $6^{\text {th }}-7^{\text {th }}$ centuries $\mathrm{AD}$, prior to the Moorish occupation [42], and the ancestral phylogenetic position of another Basque M1d sequence (Fig. 1) that does not match any African sequence. Finally, two autochthonous U6 lineages (U6b1 and U6c1) traced the origin of the Canary Islands prehispanic aborigines to Northwest Africa [43]. Although exclusive M1 lineages have not been detected in the Canary Islands, it is worth mentioning that those sampled belong to the Northwest African area [44]. Outside Africa and the Iberian Peninsula, as with U6, M1 has been mainly detected in other Mediterranean areas with main incidences in islands such as Sicily. It is customary to attribute these incidences to the above mentioned Arab/Berber historic occupations. However, taking into account the major Jewish assignation for all the M1a haplotypes detected in Europe, the possibility of a Jewish maternal ascendance for at least some of these lineages should not be rejected.

Note that the two M1 lineages sampled in the Balearic isles were of Jewish adscription [45]. Also, there were well documented Jewish settlements in Sicily since early Roman times [46] and, coincidentally, half of the M1 lineages sampled in that island $[47,48]$ belong to the M1a cluster. Finally, the Atlantic archipelagos of Canaries and Madeira, where the rigor of the Spanish Inquisition was stronger, only have $\mathrm{M} 1 \mathrm{c}$ representatives. In contrast, in the Azores Islands, that were used as a refuge by Sephardim Jews expelled from the Iberian Peninsula, half of the M1 sequences detected are of M1a assignation [49,50]. These possible Jewish contributions might be also extended to the U6 lineages of eastern origin because all U6 haplotypes detected in Ashkenazim and other Jewish groups, excepting one that is a basal U6a (16172-16219-16278), belong to the eastern Africa clade U6a1 [36,26]. An additional proof of the striking parallelism between $\mathrm{M} 1$ and U6 lineages is the fact that, as for M1, no U6 representatives were sampled in Moroccan Jews in spite of the high frequency of this clade in the Moroccan and Berber host populations [36]. 


\section{Most probable origin of $\mathrm{MI}$ ancestors}

Mitochondrial $M$ lineages in Ethiopia were first detected by RFLP analyses [51]. To explain its presence in that area the authors suggested two possibilities: 1) the marker was acquired by Ethiopians through interchanges with Asians or 2) it was present in the ancient Ethiopian population and was carried to Asia by groups who migrated out of Africa. Later, the second hypothesis was favored and a single origin of haplogroup $M$ in Africa was suggested, dating the split between Asian and African $\mathrm{M}$ branches older than 50,000 ya [22]. Although not completely discarding this last scenario other authors considered that the disjunctive was unsettled. The vast diversity of haplogroup $M$ in Asia compared to Africa pointed to the possibility that $\mathrm{M} 1$ is a branch that traces a backflow from Asia to Africa $[7,23]$. Due to the scarcity of $M$ lineages in the Near East and its richness in India, this region was proposed as the most probable origin of the M1 ancestor [7,52]. However, recent studies based on Indian mtDNA sequences [24,25] have not found any positive evidence that M1 originated in India. Nevertheless, the inclusion of M1 complete mtDNA lineages in the construction of the macrohaplogroup $M$ phylogeny clearly established that the antiquity of Indian lineages, as M2, as compared to Ethiopian M1 lineages support an Asian origin of macrohaplogroup $M$ [24]. Furthermore, the comparison within Africa of eastern and western M1 sequences left the origin of M1 in Africa uncertain [21]. On the light of our and other authors results, it seems clear that by their respective coalescence ages and diversities, M1 is younger than other Asiatic M lineages. Although it is out of doubt that the L3 ancestor of $\mathrm{M}$ had an African origin, macrohaplogroup $M$ radiated outside Africa and $\mathrm{M} 1$ should be considered an evolved branch that signals its return to this continent. Even more, as the coalescence ages of the northwestern M1c clade is older than the eastern M1a clade, we think that the most ancient dispersals of M1 occurred in northwestern Africa, reaching also the Iberian Peninsula, instead of Ethiopia. The detection of an ancestral M1C sequence in Jordanians could be explained by two alternative hypotheses: 1) that the Near East was the most probable origin of the primitive $\mathrm{M} 1$ dispersals, West into Africa and East to Central Asia. This supposition would explain the presence of basic M1 lineages, instead of the most common M1a derivates, as far as the Tibet. The actual scarcity of these types in eastern areas could be explained by posterior migrations that erased these primitive lineages. The absence of these ancestral M1c lineages in Ethiopia would point to the Sinai Peninsula as the most probable gate of entrance of this backflow to Africa. 2) That M1 is an autochthonous North African clade that had its earliest spread in northwestern areas marginally reaching the Near East and beyond. This would explain the shortage of basic M1 lineages in the Near East but would leave the Asiatic origin of the M1 ancestor undetermined. In any case, both alternatives envisaged $M$ in Africa as an offshoot of the Asiatic M trunk. The striking phylogeographic parallelism between U6 and M1 haplogroups adds additional support to these hypotheses. It is possible to correlate the dispersion ages of the different M1 clades with their contemporary climatic, archaeological, paleoanthropological and linguistic information. For instance, the first M1 backflow to Africa, dated around 30,000 ya, is coincidental with a harsh glacial period which suggests that this human retreat to Africa could be forced by climatic conditions. The low sea level in the Gibraltar Strait at that time could also facilitate the Iberian Peninsula colonization. The northwestern African M1c and the probable north central M1b expansions are coincidental with the Iberomaurusian and Capsian industries. The anomalous evolution of M1a2 lineages left the coalescence ages of the eastern Africa M1a expansion uncertain, but as suggested for the sister U6a1 radiation; these movements could be correlated in time with an African origin and expansion of Afroasiatic languages [40]. Finally, from a maternal genetic perspective it seems that Neolithic occupation of the Sahara had both eastern and western influences. Most probably other mtDNA lineages participated in this human back flow to Africa. It has been suggested that the North African X1 branch of the Euroasiatic haplogroup X could be one of them [63].

Whilst this paper was under review, a new paper also dealing with U6 and M1 haplogroups was published [53]. Haplogroup topologies and phylogeographic conclusions proposed by Olivieri et al. [53] are highly coincidental with those proposed by us in our previous paper on U6 [40] and in the present paper, dealing with M1. Regrettably, there are differences in nomenclature for $\mathrm{M} 1$. Whereas our M1 phylogeny adhered to that proposed previously by other authors [21], Olivieri et al. [53] chose to apply their own. Nevertheless, the diagnostic positions for the different M1 subhaplogroups allowed us to establish subhaplogroup homologies between the two works. Clearly their M1b subgroup (defined by transition 13111) corresponds to our M1c subgroup; their M1a2 subgroup (defined by transition 15884) corresponds to our M1b subgroup. Finally, their M1a1 subgroup (defined by transitions at 3705, 12346 and 16359) corresponds to our M1a subgroup. In addition to the reinforcing overlap of ideas, it is worthwhile mentioning the high coincidence for the coalescence ages of M1 and the majority of its subhaplogroups, when the same substitution rate [8] is used. Olivieri et al. [53] calculated a coalescence time estimate of $36.8 \pm 7.1 \mathrm{ky}$ for the entire haplogroup $\mathrm{M} 1$ that matches our estimate of $35.2 \pm 7.1 \mathrm{ky}$. Our coalescence time for M1c $(25.7 \pm 6.6 \mathrm{ky})$ also overlaps with Olivieri et al. [53] haplogroup M1b (23.4 $\pm 5.6 \mathrm{ky})$. Likewise, the coalescence age calculated for our M1a subhaplogroup $(22.6 \pm 8.1 \mathrm{ky})$ is in the range of the Olivieri et al. [53] esti- 
mation for their M1a1 subhaplogroup $(20.6 \pm 3.4 \mathrm{ky})$. The only discrepancy is about the coalescence time estimate between our M1b subhaplogroup $(13.7 \pm 4.8 \mathrm{ky})$ that is younger than that calculated by Olivieri et al. [53] for their homologous M1a2 $(24.0 \pm 5.7 \mathrm{ky})$. As our calculations are based only on three lineages and that of Oliveri et al [53] on six, we think that their coalescence time estimation should be more accurate that ours. In fact, when time estimation is based on the eight different lineages (AFR-KI43 is common to both sets) a coalescence age of $20.6 \pm 5.0 \mathrm{ky}$ is obtained. Although with overlapping errors, these results, together with the relative ancestral positions of each subgroup in the phylogenetic tree (Fig. 1 ), would suggest that the northwestern M1c clade radiation was older than those for the ubiquitous M1b and the eastern M1a clades, as also proposed by Olivieri et al. [53].

\section{Conclusion}

This study provides evidence that M1, or its ancestor, had an Asiatic origin. The earliest M1 expansion into Africa occurred in northwestern instead of northeastern areas; this early spread reached the Iberian Peninsula even affecting the Basques. The majority of the M1a lineages found outside and inside Africa had a more recent eastern Africa origin. Both western and eastern M1 lineages participated in the Neolithic colonization of the Sahara. The striking parallelism between subclade ages and geographic distribution of M1 and its North African U6 counterpart strongly reinforces this scenario. Finally, a relevant fraction of M1a lineages present today in the European Continent and nearby islands possibly had a Jewish instead of the commonly proposed Arab/Berber maternal ascendance.

\section{Methods \\ Lineages}

We have analyzed thirteen complete or nearly complete mtDNA sequences belonging to the $\mathrm{M} 1$ subhaplogroup. Eight of them are new sequences. Two were published previously [7] but have been partially re-sequenced to confirm some dubious diagnostic positions. One additional Asiatic [54] and two Ethiopian M1 sequences [55] are from other authors. In addition we analyzed 261 partial M1 sequences gathered, in a global search, from more than 38,713 published or unpublished subjects sequenced mainly for the mtDNA HVSI segment.

\section{Complete mtDNA sequencing}

Complete mtDNA were amplified in 32 overlapping fragments with primers and PCR conditions previously described [7]. The same primers were utilized to directly sequence both strands of the fragments on an ABI 3100 analyzer using Big-Dye Terminator chemistry (Applied Biosystems). Sequence data were assembled and com- pared with the SeqScape software (Applied Biosystems), and all chromatograms were visually inspected.

\section{MI phylogenetic analyses}

Phylogenetic relationships among complete mtDNA sequences were established using the reduced median network algorithm [56]. In addition to the thirteen complete or nearly complete $M 1$ sequences, a complete $M$ Indian sequence [25], assigned to the Indian subhaplogroup $\mathrm{M} 30$, was used as an outgroup.

\section{MI phylogeographic analyses}

Relationships among the different M1 haplotypes were inferred using the reduced median network algorithm [56]. To resolve reticulations, the highly recurrent mutations, $16182 \mathrm{C}, 16183 \mathrm{C}, 16093$ and the in M1 recurrent 16249, were half weighted.

\section{Differences in accumulated mutations among MI branches}

The non-parametric test, resampling probability estimates for the difference between the means of two independent samples (http://feculty.vassar.edu/lowry/Vassar Stats.html) was used to calculate the significance level of accumulated mutations between the different M1 subclades. Synonymous vs. nonsynonymous substitutions between lineages were compared by the exact-Fisher test. Differences between mean number of substitutions for coding and non-coding regions were t-Student tested.

MI diversity and differentiation within and between areas Arlequin package [57] was used to evaluate the M1 diversity within areas using molecular nucleotide diversity $(\pi)$ and gene diversity (h). AMOVA was used to test population structure. Pairwise differences between areas were obtained by means of linearized $\mathrm{F}_{\mathrm{ST}}$. Contingence tests were used to compare differences in $\mathrm{M} 1$ and $\mathrm{M} 1$ a frequencies between groups.

\section{Time estimates}

For the complete sequences only substitutions in the coding region, excluding indels, were taken into account. The mean number of substitutions per site to the most common ancestor $(\rho)$ of each clade [58] was estimated, and converted into time using two substitution rates: $1.7 \times 10^{-}$ 8 [6] and $1.26 \times 10^{-8}[8]$. For HVSI, the age of clusters or expansions was calculated as the mean divergence $(\rho)$ from inferred ancestral sequence types [58] and converted into time by assuming that one transition within $\mathrm{np}$ 16090-16365 corresponds to 20,180 years [59]. The standard deviation of the $\rho$ estimator was calculated as previously described [60]. Ages for HVSI of complete sequences were also independently calculated. 


\section{Accesion numbers}

The eight new complete mitochondrial DNA sequences are registered under GenBank accession numbers: DQ779925-32.

\section{Authors' contributions}

All the authors carried out extensive sequencing and RFLP analysis, and actively participated in the analysis and discussion of the data. In addition, JML and AMG recompiled African and Eurasian M1 sequences from published data. All the authors read and approved the final manuscript.

\section{Additional material}

\section{Additional file 1}

Appendix 1. Geographic distribution of subhaplogroup M1.

Click here for file

[http://www.biomedcentral.com/content/supplementary/1471-

2164-8-223-S1.xls

\section{Additional file 2}

Appendix 2. Reference list for the appendix 1 citations.

Click here for file

[http://www.biomedcentral.com/content/supplementary/1471-

2164-8-223-S2.doc]

\section{Acknowledgements}

This research was supported by grant BFU2006-04490 from Ministerio de Ciencia y Tecnología to J.M.L.

\section{References}

I. Stringer CB, Andrews T: Genetic and fossil evidence for the origin of modern humans. Science 1988, 239:1263-1268.

2. Hammer MF, Karafet T, Rasanayagam A, Wood ET, Altheide TK Jenkins T, Griffiths RC, Templeton AR, Zegura SL: Out of Africa and back again: nested cladistic analysis of human $Y$ chromosome variation. Mol Biol Evol 1998, 15:427-44I.

3. Underhill PA, Shen P, Lin AA, Jin L, Passarino G, Yang WH, Kauffman E, Bonné-Tamir B, Bertranpetit J, Francalacci P, Ibrahim M, Jenkins T, Kidd JR, Mehdi SQ, Seielstad MT, Wells RS, Piazza A, Davis RW, Feldman MW, Cavalli-Sforza LL, Oefner PJ: Y chromosome sequence variation and the history of human populations. Nat Genet 2000, 26(3):358-361.

4. Cann RL, Stoneking M, Wilson AC: Mitochondrial DNA and human evolution. Nature 1987, 325:31-36.

5. Chen YS, Torroni A, Excoffier L, Santachiara-Benerecetti AS, Wallace DC: Analysis of mtDNA variation in Africa populations reveals the most ancient of all human continent-specific haplogroups. Am J Hum Genet 1995, 57:133-149.

6. Ingman M, Kaessmann H, Pääbo S, Gyllensten U: Mitochondria genome variation and the origin of modern humans. Nature 2000, 408:708-713.

7. Maca-Meyer N, González AM, Larruga JM, Flores C, Cabrera VM: Major genomic mitochondrial lineages delineate early human expansions. BMC Genetics 200I, 2:13.

8. Mishmar D, Ruiz-Pesini E, Golik P, Macaulay V, Clark AG, Hosseini S, Brandon M, Easley K, Chen E, Brown MD, Sukernik RI, Olckers A, Wallace DC: Natural selection shaped regional mtDNA variation in humans. P Natl Acad Sci USA 2003, 100:171-176.

9. Knight A, Underhill PA, Mortensen HM, Zhivotovsky LA, Lin AA, Henn BM, Louis D, Ruhlen M, Mountain JL: African Y chromosome and mtDNA divergence provides insight into the history of click languages. Curr Biol 2003, 13:464-473.
10. Clark JD, Beyene Y, Woldegrabiel G, Hart WK, Renne PR, Gilbert H, Defleur A, Suwa G, Katoh S, Ludwig KR, Boisserie JR, Asfaw B, White TD: Stratigraphic, chronological and behavioural contexts of Pleistocene Homo sapiens from Middle Awash, Ethiopia. Nature 2003, 423:747-752.

II. White TD, Asfaw B, Degusta D, Gilbert H, Richards GD, Suwas G, Howell FC: Pleistocene Homo sapiens from Middle Awash, Ethiopia. Nature 2003, 423:742-747.

12. Walter RC, Buffler RT, Bruggemann JH, Guillaume MM, Berhe SM, Negassi B, Libsekal Y, Cheng H, von Cosel R, Neraudeau D, Gagnon M: Early human occupation of the Red Sea coast of Eritrea during the last interglacial. Nature 2000, 405:65-69.

13. Underhill PA, Passarino G, Lin AA, Shen P, Lahr MM, Foley RA, Oefner PJ, Cavalli-Sforza LL: The phylogeography of $Y$ chromosome binary haplotypes and the origins of modern human populations. Ann Hum Genet 200I, 65:43-62.

14. Watson E, Forster P, Richards M, Bandelt HJ: Mitochondrial footprints of human expansions in Africa. Am J Hum Genet 1997, 61:691-704.

15. Metspalu M, Kivisild T, Metspalu E, Parik J, Hudjashov G, Kaldma K, Serk P, Karmin M, Behar DM, Gilbert MT, Endicott P, Mastana S, Papiha SS, Skorecki K, Torroni A, Villems R: Most of the extant mtDNA boundaries in South and Southwest Asia were likely hsaped during the initial settlement of Eurasia by anatomically modern humans. BMC Genetics 2004, 5:26.

16. Palanichamy MG, Sun C, Agrawal S, Bandelt HJ, Kong QP, Khan F, Wang CY, Chaudhuri TK, Palla V, Zhang YP: Phylogeny of mitochondrial DNA macrohaplogroup $\mathbf{N}$ in India, based on complete sequencing: implications for the peopling of South Asia. Am J Hum Genet 2004, 75:966-978.

17. Ingman M, Gyllensten U: Mitochondrial genome variation and evolutionary history of Australian and New Guinean aborigines. Genome Res 2003, 13:1600-1606.

18. Tanaka M, Cabrera VM, González AM, Larruga JM, Takeyasu T, Fuku N, Guo L, Hirose R, Fuijta Y, Kurata M, Shinoda K, Umetsu K, Yamada Y, Oshida Y, Sato Y, Hattori N, Mizuno Y, Arai Y, Hirose N, Ohta S, Ogawa O, Tanaka Y, Kawamori R, Shamoto-Nagai M, Maruyama W, Shimokata H, Suzuki R, Shimodaira H: Mitochondrial genome variation in Eastern Asia and the peopling of Japan. Genome Res 2004, I 4: 1832-1850.

19. Forster P, Torroni A, Renfrew C, Röhl A: Phylogenetic star contraction applied to Asian and Papuan mtDNA evolution. Mol Biol Evol 200I, 18:|864-|88|.

20. Kivisild T, Rootsi S, Metspalu M, Mastana S, Kaldma K, Parik J, Metspalu E, Adojaan M, Tolk HV, Stepanov V, Golge M, Usanga E, Papiha SS, Cinnioglu C, King R, Cavalli-Sforza L, Underhill PA, Villems R: The genetic heritage of the earliest settlers persists both in Indian tribal and caste populations. Am J Hum Genet 2003, 72:313-332.

21. Kivisild T, Reidla M, Metspalu E, Rosa A, Brehm A, Pennarun E, Parik J Geberhiwot T, Usanga E, Willems R: Ethiopian mitochondrial DNA heritage: Tracking gene flow across and around the Gate of Tears. Am J Hum Genet 2004, 75:752-770.

22. Quintana-Murci L, Semino O, Bandelt HJ, Passarino G, McElreavey K Santachiara-Benerecetti AA: Genetic evidence of an early exit of Homo sapiens sapiens from Africa through eastern Africa. Nat Genet 1999, 23:437-441.

23. Tambets K, Kivisild T, Metspalu E, Parik J, Kaldma K, Laos S, Tolk HV Gölge M, Demirtas H, Geberhiwot T, Papiha SS, de Stefano GF, Villems $\mathrm{R}$ : The topology of the maternal lineages of the Anatolian and Trans-Caucasus populations and the peopling of Europe: Some preliminary considerations. In Archaeogenetics: DNA and the population prehistory of Europe Edited by: Renfrew C, Boyle K. Cambridge, UK: McDonald Institute for Archaeological Research, University of Cambridge; 2000:2 19-235.

24. Rajkumar R, Banerjee J, Gunturi HB, Trivedi R, Kashyap VK: Phylogeny and antiquity of $M$ macrohaplogroup inferred from complete $m$ tDNA sequence of Indian specific lineages. BMC Evol Biol 2005, 5:26.

25. Sun C, Kong QP, Palanichamy MG, Agrawal S, Bandelt HJ, Yao YG Khan F, Zhu CL, Chaudhuri TK, Zhang YP: The dazzling array of basal branches in the mtDNA macrohaplogroup M from India as inferred from complete genomes. Mol Biol Evol 2006, 23:683-690

26. Shen P, Lavi T, Kivisild T, Chou V, Sengun D, Gefel D, Shpirer I, Woolf E, Hillel J, Feldman MW, Oefner PJ: Reconstruction of patrilineages and matrilineages of Samaritans and other Israeli populations from Y-chromosome and mitochondrial DNA sequence variation. Hum Mutation 2004, 24:248-260.

27. Quintana-Murci L, Chaix R, Wells RS, Behar DM, Sayar H, Scozzari R, Rengo C, Al-Zahery N, Semino O, Santachiara-Benerecetti AS, Coppa A, Ayub Q, Mohyuddin A, Tyler-Smith C, Qasim Mehdi S, Torroni A, McElreavey K: Where West meets East: The complex mtDNA 
landscape of the Southwest and Central Asian corridor. Am J Hum Genet 2004, 74:827-845.

28. Kivisild T, Kaldma K, Metspalu M, Parik J, Papiha SS, Villems R: The place of the Indian mitochondrial DNA variants in the global network of maternal lineages and the peopling of the Old World. In Genomic diversity Edited by: Deka R, Papiha SS. New York: Kluwer/Academic/Plenum Publishers; 1 999:135-152.

29. Bermisheva MA, Kutuev IA, Korshunova TY, Dubova NA, Villems R Khusnutdinova EK: Phylogeographic analysis of mitochondrial DNA in the Nogays: A strong mixture of maternal lineages from eastern and western Eurasia. Molec Biol 2004, 38:5I6-523.

30. Comas D, Calafell F, Mateu E, Pérez-Lezaun A, Bosch E, Martínez-Arias R, Clarimon J, Facchini F, Fiori G, Luiselli D, Pettener D, Bertranpetit $\mathrm{J}$ : Trading genes along the silk road: mtDNA sequences and the origin of Central Asian populations. Am J Hum Genet 1998 , 63:1824-1838.

31. Yao YG, Zhang YP: Phylogeographic analysis of mtDNA variation in four ethnic populations from Yunnan province: new data and a reappraisal. J Hum Genet 2002, 47:3|I-3I8.

32. Fucharoen G, Fucharoen S, Horai S: Mitochondrial DNA polymorphism in Thailand. J Hum Genet 200I, 46:II5-I25

33. Yao YG, Kong QP, Bandelt HJ, Kivisild T, Zhang YP: Phylogeographic differentiation of mitochondrial DNA in Han chinese. Am J Hum Genet 2002, 70:635-65I.

34. Malyarchuk B, Derenko M, Grzybowski T, Lunkina A, Czarny J, Rychkow S, Morozova I, Denisova G, Miscicka-Sliwka D: Differentiation of mitochondrial DNA and Y chromosomes in Russian populations. Hum Biol 2004, 76:877-900.

35. Richards M, Macaulay V, Hickey E, Vega E, Sykes B, Guida V, Rengo C Sellitto D, Cruciani F, Kivisild T, Villems R, Thomas M, Rychkov $S$, Rychkov O, Rychkov Y, Golge M, Dimitrov D, Hill E, Bradley D, Romano V, Cali F, Vona G, Demaine A, Papiha S, Triantaphyllidis C, Stefanescu G, Hatina J, Belledi M, Di Rienzo A, Novelletto A, Oppenheim A, Norby S, Al-Zaheri N, Santachiara-Benerecetti S, Scozari R, Torroni A, Bandelt $\mathrm{H}$ ): Tracing European founder lineages in the Near Eastern mtDNA pool. Am J Hum Genet 2000, 67: I 25I-1276.

36. Thomas MG, Weale ME, Jones AL, Richards M, Smith A, Redhead N Torroni A, Scozzari R, Gratix F, Tarekegn A, Wilson JF, Capelli C Bradman N, Goldstein DB: Founding mothers of Jewish communities: Geographically separated Jewish groups were independently founded by very few female ancestors. Am J Hum Genet 2002, 70: |4| I-1420.

37. Behar DM, Hammer MF, Garrigan D, Villems R, Bonne-Tamir B, Richards M, Gurwitz D, Rosengarten D, Kaplan M, Pergola SD, QuintanaMurci L, Skorecki K: MtDNA evidence for a genetic bottleneck in the early history of the Ashkenazi Jewish population. Eur Hum Genet 2004, I 2:355-364.

38. Behar DM, Metspalu E, Kivisild T, Achilli A, Hadid Y, Tzur S, Pereira L, Amorim A, Quintana-Murci L, Majamaa K, Herrnstadt C, Howell N, Balanovsky O, Kutuev I, Pshenichnov A, Gurwitz D, Bonne-Tamir B, Torroni A, Villems R, Skorecki K: The matrilineal ancestry of Ashkenazi Jewry: Portrait of a recent founder event. Am J Hum Genet 2006, 78:487-497.

39. Torroni A, Rengo C, Guida V, Cruciani F, Sellito D, Coppa A, Calderon FL, Simionati B, Valle G, Richards M, Macaulay V, Scozzari R: Do the four clades of the mtDNA haplogroup L2 evolve at different rates? Am J Hum Genet 200I, 69:1348-1356.

40. Maca-Meyer N, González AM, Pestano J, Flores C, Larruga JM, Cabrera VM: Mitochondrial DNA transit between West Asia and North Africa inferred from U6 phylogeography. BMC Genetics 2003, 4:15

41. Howell N, Elson JL, Turnbull DM, Herrnstadt C: African haplogroup L mtDNA sequences show violations of clock-like evolution. Mol Biol Evol 2004, 21:1843-1854.

42. Alzualde $\mathrm{A}$, lzaguirre $\mathrm{N}$, Alonso S, Alonso A, Albarrán C, Azcarate $\mathrm{A}$ de la Rúa C: Insights into the "isolation" of the Basques: mtDNA lineages from the historical site of Aldaieta $\left(6^{\text {th }}-7^{\text {th }}\right.$ centuries AD). Am J Phys Anthrop 2006, 130:394-404

43. Maca-Meyer N, Arnay M, Rando JC, Flores C, González AM, Cabrera VM, Larruga JM: Ancient mtDNA analysis and the origin of the Guanches. Eur J Hum Genet 2004, 1 2:155-162.

44. Rando JC, Cabrera VM, Larruga JM, Hernández M, González AM, Pinto $\mathrm{F}$, Bandelt $\mathrm{HJ}$ : Phylogeographic patterns of mtDNA reflecting the colonization of the Canary Islands. Ann Hum Genet 1999, 63:413-428

45. Picornell A, Gómez-Barbeito L, Tomas C Castro JA, Ramón MM: Mitochondrial DNA HVRI variation in Balearic populations. Am J Phys Anthropol 2005, I 28:1 19-130.

46. Pergola SD: The geography of Italian Jews: countrywide patterns. In In Studi sull'ebraismo italiano Edited by: Toaff E Roma: Instituto Superiore di Studi Ebraici del Collegio Rabbinico Italiano: 1974:93-128
47. Cali F, Le Roux MG, D'Anna R, Flugy A, De Leo G, Chiavetta V, Ayala GF, Romano V: MtDNA control region and RFLP data for Sicily and France. Int J Legal Med 200I, I 1 4:229-23I.

48. Forster P, Cali F, Röhl A, Metspalu E, D'Anna R, Mirisola M, De Leo G Flugy A, Salerno A, Ayala G, Kouvatsi A, Villems R, Romano V: Continental and subcontinental distributions of mtDNA control region types. Int J Legal Med 2002, I I 6:99-108.

49. Brehm A, Pereira L, Kivisild T, Amorim A: Mitochondrial portraits of the Madeira and Accores archipelagos witness different genetic pools of its settlers. Hum Genet 2003, I I 4:77-86.

50. Santos C, Lima M, Montiel R, Angles N, Pires L, Abade A, Aluja MaP: Genetic structure and origin of peopling in the Azores Islands (Portugal): The view from mtDNA. Ann Hum Genet 2003, 67:433-456.

51. Passarino G, Semino O, Quintana-Murci L, Excoffier L, Hammer M, Santachiara-Benerecetti AS: Different genetic components in the Ethiopian population, identified by mtDNA and Y-chromosome polymorphisms. Am J Hum Genet 1998, 62:420-434.

52. Roychoudhury S, Roy S, Basu A, Banerjee R, Vishwanathan H, Usha Rani MV, Sil SK, Mitra M, Majumder PP: Genomic structures and population histories of linguistically distinct tribal groups of India. Hum Genet 200I, 109:339-350

53. Olivieri A, Achilli A, Pala M, Battaglia V, Fornarino S, Al-Zahery N, Scozzari R, Cruciani F, Behar DM, Dugoujon JM, Coudray C, Santachiara-Benerecetti AS, Semino O, Bandelt HJ, Torroni A: The mtDNA legacy of the Levantine early Upper Palaeolithic in Africa. Science 2006, 3 |4:1767-1770.

54. Herrnstadt C, Elson JE, Fahy E, Preston G, Turnbull DM, Anderson C Ghosh SS, Olefsky JM, Beal MF, Davis RE, Howell N: Reduced median-network analysis of complete mitochondrial DNA coding-region sequences for the major African, Asian and European haplogroups. Am J Hum Genet 2002, 70: I I52-I I7I.

55. Kivisild T, Shen P, Wall D, Do B, Sung R, Davis K, Passarino G, Underhill PA, Scharfe C, Torroni A, Scozzari R, Modiano D, Coppa A, de Kniiff P, Feldman M, Cavalli-Sforza LL, Oefner PJ: The role of selection in the evolution of human mitochondrial genomes. Genetics 2006, 172:373-387.

56. Bandelt $\mathrm{H}$-J, Forster $\mathrm{P}, \mathrm{Röhl} \mathrm{A}$ : Median-joining networks for inferring intraspecific phylogenies. Mol Biol Evol 1999, 16:37-48.

57. Schneider S, Roessli D, Excoffier L: Arlequin ver. 2.000: A software for population genetics data analysis Genetics and Biometry Laboratory. Switzerland: University of Geneva; 2000.

58. Morral N, Bertranpetit J, Estivill X, Nunes V, Casals T, Giménez J, Reis A, Varon-Mateeva R, Macek M, Kalaydjieva L, et al.: The origin of the major cystic fibrosis mutation $(\triangle F 508)$ in European populations. Nat Genet 1994, 7:169-175.

59. Forster $\mathrm{P}$, Harding R, Torroni A, Bandelt $\mathrm{HJ}$ : Origin and evolution of Native American mtDNA variation: a reappraisal. Am J Hum Genet 1996, 59:935-945.

60. Saillard J, Forster P, Lynnerup N, Bandelt HJ, Norby S: MtDNA variation among Greenland eskimos: the edge of the Beringian expansion. Am J Hum Genet 2000, 67:718-726.

61. Anderson S, Bankier AT, Barrell BG, de Bruijn MH, Coulson AR, Drouin I, Eperon IC, Nierlich DP, Roe BA, Sanger F, Schreier PH, Smith AJ, Staden R, Young IG: Sequence and organisation of the human mitochondrial genome. Nature 198I, 290:457-465.

62. Andrews RM, Kubacka I, Chinnery PF, Lightowlers RN, Turnbull DM, Howell N: Reanalysis and revision of the Cambridge reference sequence for human mitochondrial DNA. Nat Genet 1999, 23:147.

63. Reidla M, Kivisild T, Metspalu E Kaldma K, Tambets K, Tolk HV, Parik J, Loogväli EL, Derenko M, Malyarchuk B, Bermisheva M, Zhadanov S, Pennarun E, Gubina M, Golubenko M, Damba L, Fedorova S, Gusar V Grechanina E, Mikerezi I, Moisan IP, Chaventré A, Khusnutdinova E, Osipova L, Stepanov V, Voevoda M, Achilli A, Rengo C, Rickards O, De Stefano GF, Papiha S, Beckman L, Janicijevic B, Rudan P, Anagnou N, Michalodimitrakis E, Koziel S, Usanga E, Geberhiwot T, Herrnstadt C, Howell N, Torroni A, Villems R: Origin and diffusion of mtDNA haplogroup X. Am J Hum Genet 2003, 73: I I78-II90. 